\title{
Analytical Modeling and Results Evaluation of Composite Open Web Steel Joists Behavior
}

\author{
Ali Farhan Hadeed \\ Building and Construction \\ Technology Eng. Dep. \\ Al-Esra'a University College, \\ Baghdad, IRAQ \\ Laith Khalid Al-Hadithy \\ Civil Engineering Dep. \\ Al-Nahrain University, \\ Baghdad, IRAQ \\ thadithy@yahoo.com
}

engalifarhan@yahoo.com

Received: $26-$ Oct.-2017

http://doi.org/10.29194/NJES.21030356
Revised: 23-Jan.-2018

\author{
Riyadh J. Aziz \\ Architecture Dep. \\ Al- Esra'a University College, \\ Baghdad, IRAQ \\ riyadhaziz48@yahoo.com
}

Accepted: 30-April-2018

\begin{abstract}
In this study, the analytic model (Azmi Model) had been considered for computation the load capacities of the composite open web steel joists and compared them with those obtained from experimental tests. The capacities of seven joists had been studied, each including one of the following variables (distribution of headed studs, connection degree of the connectors, inclination of the web, shape of the web, density of slab concrete, length of connectors).Theoretically, according to the Analytic model, the referenced joist of $\left(45^{\circ}\right.$ web inclination, uniformly distributed, over connected, short headed studs) exhibited maximum load capacity of (18.45) ton, while the joist of $\left(45^{\circ}\right.$ web inclination, uniformly distributed, under connected, short headed studs) exhibited minimum load capacity of (16.23) ton at yield point of bottom chord. Experimentally, the referenced joist exhibited maximum load capacity of $(15.51)$ ton, while the joist of $\left(34^{\circ}\right.$ web inclination, uniformly distributed, over connected, short headed studs) exhibited (12.49) ton load capacity. The load capacities values of the tested joists ranged between $(67 \%-85 \%)$ of the predicted values according to the analytic model.
\end{abstract}

Keywords: Composite, Open Web, Steel Joists, Analytical Modeling

\section{Composite Open Web Steel Joist Definition}

The term composite joist(CJ Series) refers to open web, parallel chord, load carrying members utilizing hot-rolled or cold-formed steel, including cold-formed steel whose yield strength has been attained by cold working, suitable for the direct support of floors of one - way floor or roof systems. Shear connection between the joist top chord and overlying concrete slab allows the steel joist and concrete slab to act together as integral unit after the concrete has adequately been cured $^{1,2}$

\section{Experimental Work Review}

Seven joists were configured as in Fig.1 and Fig.2.Their capacities had been studied experimentally by the flexural test machine of $3000 \mathrm{kN}$ capacity with load increment of $10 \mathrm{kN}$ as depicted in Fig. 3 and plate 1. Each joist includes one of the following variables which they are; (distribution of headed studs, degree of the connection, inclination of the web, shape of the web, density of slab either normal weight concrete (NWC) or light weight concrete (LWC) and length of shear connectors). Member strains were recorded for each load stage using strain gauges fixed at the members where pointed in Fig.4 .Data logger was used for gathering strain values, that shown in plate1.Top and bottom chord yield forces are given in table1, also experimental applied load and internal chord forces at yield stage of bottom chord are recorded in table 2 .

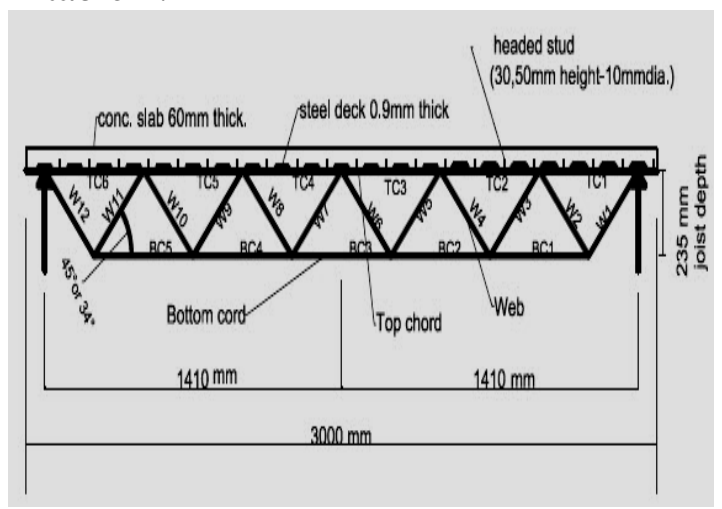

Figure 1: Typical joist configuration 


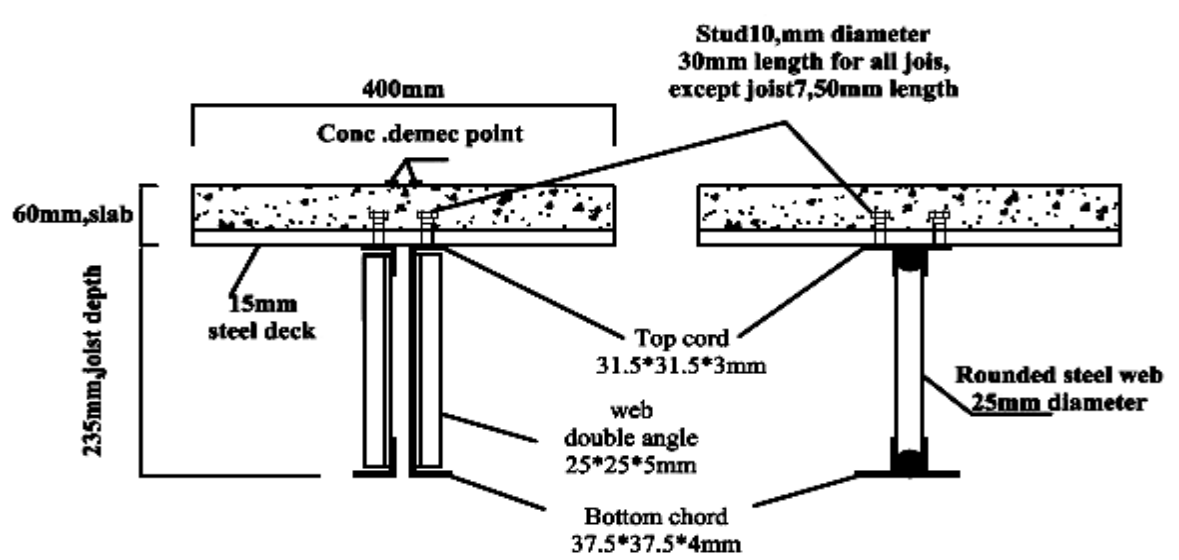

a-Cross section for josts $1,2,3,4,6,7$

b-Cross section for joist5

Figure 2: Joists cross section

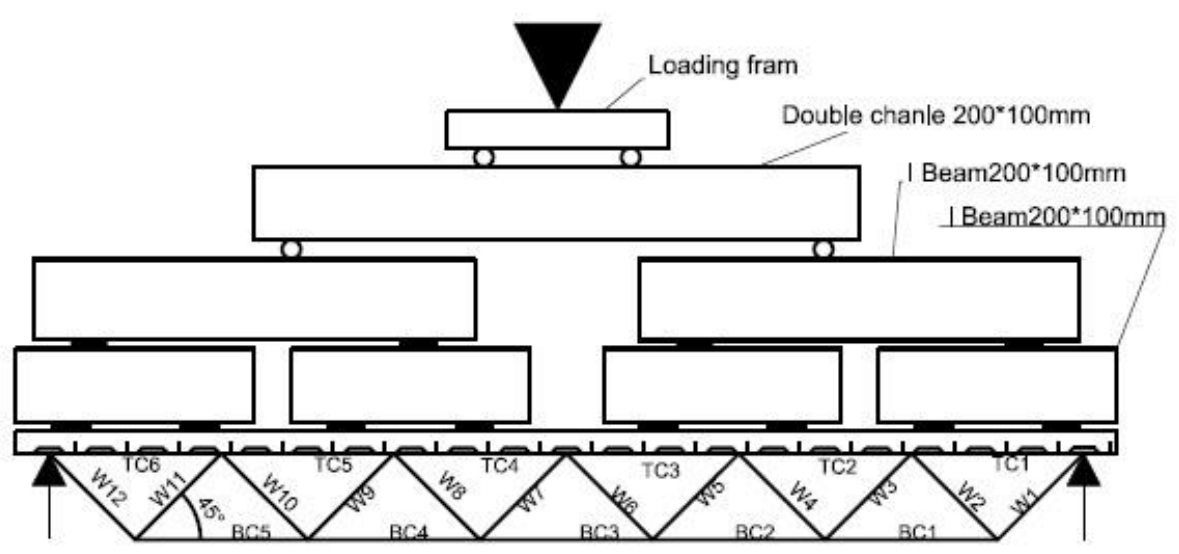

Figure 3: Loading arrangement

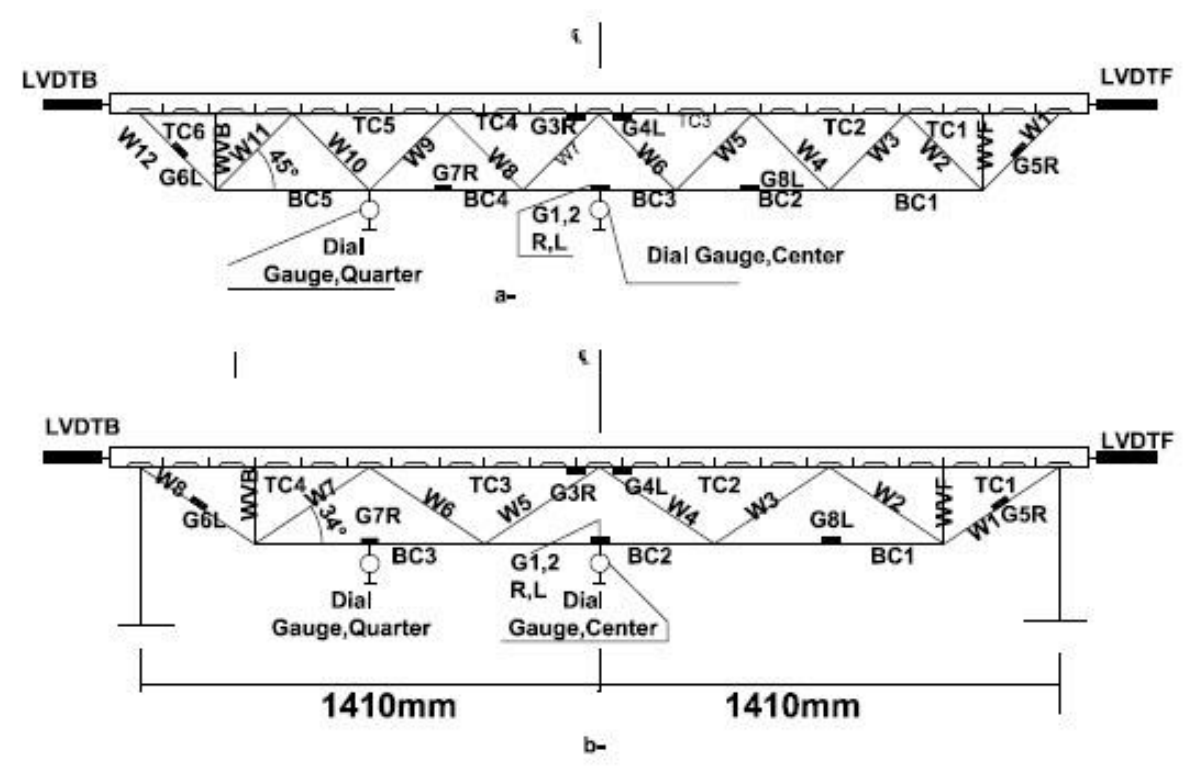

Figure 4: Members designation and strain gauges locations a- joists $(1,2,3,5,6,7)$, b- joist 4 


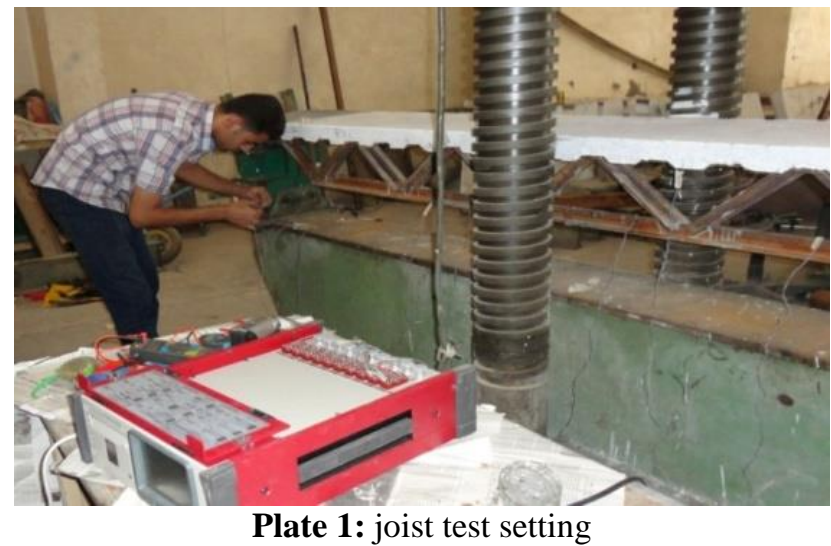

Table 1: Top and bottom chord yield forces

\begin{tabular}{|c|c|c|c|c|c|c|}
\hline Joiss & $\boldsymbol{A}_{\boldsymbol{t c}}\left(\boldsymbol{m m}^{\mathbf{2}}\right)$ & $\boldsymbol{A}_{\boldsymbol{b c}}\left(\mathbf{m m}^{\mathbf{2}}\right)$ & $\boldsymbol{f}_{\boldsymbol{y t c}}(\boldsymbol{M p a})$ & $\boldsymbol{f}_{\boldsymbol{y b c} \boldsymbol{c}}(\boldsymbol{M p a})$ & $\boldsymbol{N}_{\boldsymbol{y}}(\boldsymbol{k N})$ & $\boldsymbol{T}_{\boldsymbol{y}}(\boldsymbol{k N})$ \\
\hline CSJ-1 & 383.225 & 572.9 & 348.39 & 324 & 133.5 & 185.62 \\
\hline CSJ-2 & 383.225 & 572.9 & 348.39 & 324 & 133.5 & 185.62 \\
\hline CSJ-3 & 383.225 & 572.9 & 348.39 & 324 & 133.5 & 185.62 \\
\hline CSJ-4 & 383.225 & 572.9 & 348.39 & 324 & 133.5 & 185.62 \\
\hline CSJ-5 & 383.225 & 490.25 & 348.39 & 324 & 133.5 & 185.62 \\
\hline CSJ-6 & 383.225 & 572.9 & 348.39 & 324 & 133.5 & 185.62 \\
\hline CSJ-7 & 383.225 & 572.9 & 348.39 & 324 & 133.5 & 185.62 \\
\hline
\end{tabular}

$\mathrm{A}_{\mathrm{tc}}, \mathrm{A}_{\mathrm{bc}}$ Top and bottom chord cross-sectional area respectively

$\mathrm{f}_{\mathrm{ytc}}, \mathrm{f}_{\mathrm{ybc}}$ Top and bottom chord yield stress respectively, taken from laboratory test

$\begin{array}{cc}\mathrm{T}_{\mathrm{y}} & \text { Bottom chord yield force } \\ \mathrm{N}_{\mathrm{y}} & \text { Top chord yield force }\end{array}$

Table 2: Experimental applied load and internal chord forces at yield stage of bottom chord

\begin{tabular}{|c|c|c|c|c|c|c|}
\hline \multirow[b]{2}{*}{$\stackrel{\bar{n}}{\cdot \frac{\pi}{\sigma}}$} & \multirow[b]{2}{*}{$\begin{array}{l}p_{a e} \\
\text { kN }\end{array}$} & \multicolumn{2}{|c|}{ Bottom chord } & \multicolumn{2}{|c|}{ Top chord } & \multirow{2}{*}{$\begin{array}{c}\text { Web member } \\
\text { Web Strain } \\
\mu \varepsilon\end{array}$} \\
\hline & & $\begin{array}{c}\text { Strain } \\
\boldsymbol{\mu} \varepsilon\end{array}$ & $\begin{array}{l}T_{a e} \\
k N\end{array}$ & $\begin{array}{c}\text { Strain } \\
\mu \varepsilon\end{array}$ & $\begin{array}{l}N_{a e} \\
k N\end{array}$ & \\
\hline $\mathrm{J} 1$ & 151.35 & 1620.005 & 185.6202 & 727.29 & 55.74 & 642.11(Tension) \\
\hline $\mathrm{J} 2$ & 137.7 & 1620.207 & 185.643 & 366.815 & 28.14 & 510.98(Compression) \\
\hline $\mathrm{J} 3$ & 134.6 & 1620.099 & 185.630 & 521.3 & 39.93 & 392.59(Tension) \\
\hline $\mathrm{J} 4$ & 121.22 & 1620.02 & 185.622 & 387.344 & 29.7 & 684.344(Tension) \\
\hline $\mathrm{J} 5$ & 147.5 & 1620.044 & 185.625 & 601.25 & 46.1 & 844.5(Compression) \\
\hline J6 & 130.03 & 1620.031 & 185.623 & 246.174 & 18.87 & 639.483(Compression) \\
\hline $\mathrm{J} 7$ & 133.25 & 1620.042 & 185.624 & 252.25 & 19.33 & 639.76(Tension) \\
\hline
\end{tabular}

$\mathrm{p}_{\mathrm{ae}}$ Experimental applied load

$\mathrm{T}_{\mathrm{ae}}$ Experimental bottom chord force due to applied load

$\mathrm{N}_{\mathrm{ae}}$ Experimental top chord force due to applied load

$\mathrm{T}_{\mathrm{ae}}, \mathrm{N}_{\mathrm{ae}}=$ bottom or top chord strain reading*steel elastic modulus $*$ chord cross sectional area

\section{Theoretical Aspects}

Calculated moment capacities for the composite joists in this study are based on the ultimate strength models presented by Azmi $(1972)^{3}$ as shown in Fig.5. This model also was adopted by Douglas F. Lauer (1994) ${ }^{4}$. Two categories, "Over-connected" and "underconnected", are designated by how the supplied amount of the shear connection, $\Sigma Q$, compares to the yield force of the bottom chord, $\boldsymbol{T}_{\boldsymbol{y}}$.Under connected joists have a shear connection force less than the bottom chord yield force $\left(\sum \mathrm{Q}<\boldsymbol{T}_{\boldsymbol{y}}\right)$ ; over connected joists have a shear force greater than the bottom chord yield force $\left(\sum \mathrm{Q}>\boldsymbol{T}_{\boldsymbol{y}}\right)$. An amount of shear connection equal to the yield force of the bottom chord $\left(\sum \mathrm{Q}=\boldsymbol{T}_{\boldsymbol{y}}\right)$, is the 
NJES Vol.21 No.3, 2018

transition point between under-connected and over - connected and is assigned the value $100 \%$ shear connection. This condition is shown as a third category termed "balanced". It can be noticed that the balanced case is just a unique situation between under connected and over connected where the supplied shear connection, $\sum \mathrm{Q}$ balances the yield force of the bottom chord $\boldsymbol{T}_{\boldsymbol{y}}$. The balanced model is only included to show its central position and to clearly define the configuration against which the others are measured. The degree to which the joist is under-

\section{Hadeed et al., pp.356-367}

or over connected determines the magnitude of the top chord. It is assumed in the models that the top chord will be utilized to the extent necessary to satisfy horizontal force equilibrium, not exceeding $\boldsymbol{N}_{\max }$, the maximum compression or tension force achievable in the top chord. With case 1 and case 5, the most under-connected and over-connected, the top chord is fully developed in compression or tension respectively. Cases 2, 3 and 4 , the intermediate cases, require only a portion of the forces available in the top chord for equilibrium of forces.

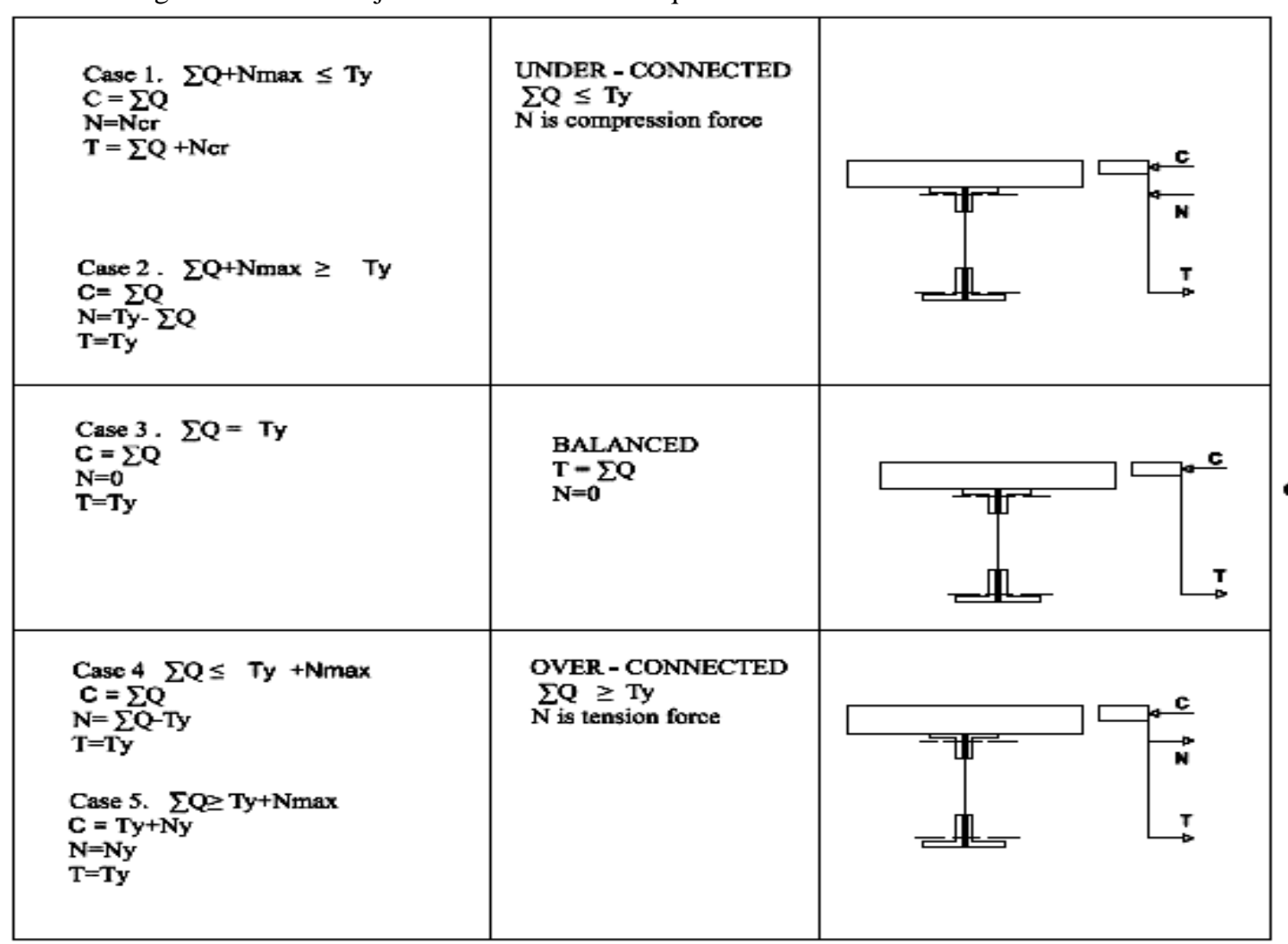

Figure 5: Flexural models (Adopted from Azmi (1972)) ${ }^{\mathbf{3}}$

\section{Procedure for Analysis}

Two series of computations were carried out in evaluating the joists, the first based on calculated (predicted) values, and the second based on experimental (measured) values. The variables that are analyzed in each series of calculations are: $\boldsymbol{C}, \boldsymbol{N}, \boldsymbol{T}$-internal forces, $\boldsymbol{M}$-Mid span moment, $\boldsymbol{P}$-joist load. The experimental values are compared to the calculated values to test the accuracy of the flexural models. The notation used for the calculated and experimental variables at each loading stages is summarized in table 3. Predicted values are calculated at the dead load stage and at the total load stage. The predicted applied load values are found by subtracting the dead load forces and moments from the load forces and moments. The ultimate load calculations are typically strength analysis in which the internal forces are the starting values, and the moment capacity of the section is to be determined using the ultimate strength models from Fig. 6. Knowing the moment capacity, the member load that can be carried is back calculated using statics. This progression of calculations can be shown diagrammatically as,

$$
C_{c}, N_{c}, T_{c} \stackrel{\text { model }}{\longrightarrow} M_{c} \stackrel{\text { statics }}{\longrightarrow} P_{c}
$$

Experimental values are measured at the dead load stage and the applied stage.

The applied load response is superimposed on the dead load response to obtain the experimental total forces and moments that can be compared to the predicted values previously calculated. The evaluation of the experimental applied is reverse of the previous method and can be shown diagrammatically as

$$
P_{a e} \stackrel{\text { statics }}{\longrightarrow} M_{a e} \stackrel{\text { model }}{\longrightarrow} C_{a e}, N_{a e}, T_{a e}
$$


where the subscript $\boldsymbol{a} \boldsymbol{e}$ is used because the evaluation is preformed at the applied load stage using experimental values. The experimental applied member load, $\boldsymbol{P}_{\boldsymbol{a} e}$ is converted to the midspan moment using static. Knowing the moment, the internal resisting forces, which must be present, can be back calculated using the appropriate flexural model. This sequence of the calculations begins with the experimental member load. Therefore, it cannot begin until after the test results are obtained. The majority of the joists for this study are over-connected. Only joist 3 was considered under connected. Joists $1,2,4,5$ and 6 are classified as case 4 , while joist 7 are classified as case 5.Joist 3 is classified as Case 2.This study is an analysis of experimental results and as such does not include any load factors, resistance factors, or factor of safety.

Table 3: Summary of the Analysis Notation

\begin{tabular}{|c|c|c|c|c|}
\hline & & \multicolumn{3}{|c|}{ Loading Stage } \\
\hline & & Dead & Applied & Total \\
\hline \multirow{5}{*}{ General } & Slab Force & -- & $C_{a}$ & $C$ \\
\hline & Top Chord Force & $N_{d}$ & $N_{a}$ & $N$ \\
\hline & Bottom Chord Force & $T_{d}$ & $T_{a}$ & $T$ \\
\hline & Midspan Moment & $M_{d}$ & $M_{a}$ & $M$ \\
\hline & Member Load & $P_{d}$ & $P_{a}$ & $P$ \\
\hline \multirow{5}{*}{ Calculated } & Slab Force & -- & $C_{a c}$ & $C_{c}$ \\
\hline & Top Chord Force & $N_{d c}$ & $N_{a c}$ & $N_{c}$ \\
\hline & Bottom Chord Force & $T_{d c}$ & $T_{a c}$ & $T_{c}$ \\
\hline & Midspan Moment & $M_{d c}$ & $M_{a c}$ & $M_{c}$ \\
\hline & Member Load & $P_{d c}$ & $P_{a c}$ & $P_{c}$ \\
\hline \multirow{5}{*}{ Experimental } & Slab Force & -- & $C_{a e}$ & $C_{e}$ \\
\hline & Top Chord Force & $N_{d e}$ & $N_{a e}$ & $N_{e}$ \\
\hline & Bottom Chord Force & $T_{d e}$ & $T_{a e}$ & $T_{e}$ \\
\hline & Midspan Moment & $M_{d e}$ & $M_{a e}$ & $M_{e}$ \\
\hline & Member Load & $P_{d e}$ & $P_{a e}$ & $P_{e}$ \\
\hline
\end{tabular}

\section{Application and Calculated Values 5.1 Calculated Shear Connectors Resistance}

composite beams the slab force is controlled by the shear connection capacity rather than the compressive strength of the concrete .Similarly, for those composite joist cases where the compression force $\boldsymbol{C}$ is taken to its limit (cases 1 , 2,3 and that the concrete crushing strength is greater than the shear connector force. Because the connection controls the slab compressive force, it can be said that $\boldsymbol{C}_{\boldsymbol{a}}=\sum \boldsymbol{Q}_{\boldsymbol{a c}}$ and $\boldsymbol{C}_{\boldsymbol{c}}=$ $\sum \boldsymbol{Q}_{c}$.Also , because the slab compressive force does not occur at the dead load stage, the slab compressive force under applied load is interchangeable with that under total load, that is $\boldsymbol{C}_{\boldsymbol{a}}=\boldsymbol{C}_{\boldsymbol{c}}$ and $\sum \boldsymbol{Q}_{\boldsymbol{a c}}=\sum \boldsymbol{Q}_{\boldsymbol{c}}$. The first step in analyzing a composite joist is the calculation of the shear connection force and the bottom chord yield force to enable the proper classification to be selected. In estimating the shear connection force of the test specimens, both analytical and experimental techniques were used .The common forms of shear connection were predicted analytically using established formulas according to codes. For the less common shear connectors, push-out test results were used to determine the amount of shear connection strength per stud (Q).
Calculation of the total shear values per half span ( $\sum \mathbf{Q}_{\mathbf{c}}$ ) in this study based on push-out tests according to the British standards ${ }^{5}$, knowing that 10 studs per half span for over connection and 5 studs per half span were used. According to that: Joist 1-shear connection strength $\sum \mathrm{Q}_{\mathrm{c}}=30 \mathrm{kN} * 10$ studs/half joist length $=300 \mathrm{kN}$

Joist 2-shear connection strength $\sum \mathrm{Q}_{\mathrm{c}}=30 \mathrm{kN} * 10$ studs/half joist length $=300 \mathrm{kN}$

Joist 3-shear connection strength $\sum \mathrm{Q}_{\mathrm{c}}=30 \mathrm{kN} * 5$ studs/half joist length $=150 \mathrm{kN}$

Joist 4-shear connection strength $\sum \mathrm{Q}_{\mathrm{c}}=30 \mathrm{kN} * 10$ studs/half joist length $=300 \mathrm{kN}$

Joist 5-shear connection strength $\sum \mathrm{Q}_{\mathrm{c}}=30 \mathrm{kN} * 10$ studs/half joist length $=300 \mathrm{kN}$

Joist6-shear connection strength $\sum \mathrm{Q}_{\mathrm{c}}=26.5 \mathrm{kN} * 10$ studs/half joist length $=265 \mathrm{kN}$

Joist 7-shear connection strength $\sum \mathrm{Q}_{\mathrm{c}}=35 \mathrm{kN} * 10$ studs/half joist length $=350 \mathrm{kN}$

\subsection{Calculated Chord Forces}

Knowledge of the bottom chord yield force is necessary to determine whether a joist is under or over- connected .The bottom chord yield strength $\boldsymbol{T}_{\boldsymbol{y}}$ was calculated by the results of the tensile coupon tests reported in Tables 1.The degree to which a joist is under or over connected can be represented by the ratio $\sum \boldsymbol{Q}_{c} / \boldsymbol{T}_{\boldsymbol{y}}$ and shown in table 4. The symbol ( $\left.\boldsymbol{N}_{\max }\right)$ denotes the maximum available tension or compression 


\section{NJES Vol.21 No.3, 2018}

force. For over-connected joists the top chord is in tension at failure and the top chord capacity $\left(\boldsymbol{N}_{\max }\right.$ ) is the yield force $\boldsymbol{N}_{\boldsymbol{y}}$. For under - connected joists the top chord is in compression at failure

\section{Hadeed et al., pp.356-367}

and the top chord capacity ( $\boldsymbol{N}_{\max }$ ) is the buckling load $N_{c r}$ also considered $\left(N_{y}\right)$ as depicted in Fig.5.

Table 4: Joists classification according to the condition of shear connection

\begin{tabular}{|c|c|c|c|c|c|}
\hline Joist & $\begin{array}{c}\sum \boldsymbol{Q}_{\boldsymbol{c}} \\
(\boldsymbol{k} \boldsymbol{N})\end{array}$ & $\begin{array}{c}\boldsymbol{N}_{\boldsymbol{y}} \\
(\boldsymbol{k} \boldsymbol{N})\end{array}$ & $\begin{array}{c}\boldsymbol{T}_{\boldsymbol{y}} \\
(\boldsymbol{k} \boldsymbol{N})\end{array}$ & $\Sigma \boldsymbol{Q}_{\boldsymbol{c}} / \boldsymbol{T}_{\boldsymbol{y}}$ & shear connection Case \\
\hline CSJ-1 & 300 & 133.5 & 185.620 & 1.62 & Over connection - 44 \\
\hline CSJ-2 & 300 & 133.5 & 185.620 & 1.62 & Over connection - 4 \\
\hline CSJ-3 & 150 & 133.5 & 185.620 & 0.81 & under connection -2 \\
\hline CSJ-4 & 300 & 133.5 & 185.620 & 1.62 & Over connection - 4 \\
\hline CSJ-5 & 300 & 133.5 & 185.620 & 1.62 & Over connection - 4 \\
\hline CSJ-6 & 265 & 133.5 & 185.620 & 1.43 & Over connection - 4 \\
\hline CSJ-7 & 350 & 133.5 & 185.620 & 1.89 & Over connection -5 \\
\hline
\end{tabular}

The specimens are divided into five cases which depend on the maximum tension force available in the top chord if the joist is over-connected and the maximum compression force available in the top chord if the joist is under-connected as in Fig.5. Assuming that the shear connection force and top chord capacity are accurately predicted, it can be determined that joists, 1,2,4,5 and 6 are in case 4 , joist 3 is in case 2 and joist 7 is in Case 5 as shown in table 4.Calculation of the bottom and top chord yield forces $\boldsymbol{N}_{\boldsymbol{y}}$ and $\boldsymbol{T}_{\boldsymbol{y}}$ is summarized in Tables 5 and 6 respectively. Calculated chord forces due to dead load were found by computing according to the equation:

$$
N_{d c}=M_{d c} / e^{\prime}=\left(T_{d c}\right)
$$

The chord force available to resist applied loads is the difference between the total load at failure and the force existing in the chord from dead load.

$$
\begin{array}{lr}
N_{a c}=N_{c}-N_{d c} & \ldots .2 \\
T_{a c}=T_{c}-T_{d c} & \ldots .3
\end{array}
$$

This reduces the capacity of the chord by the amount consumed by the dead load.The reduction is most important in the chord, for the tested joist in this study. The top chord and bottom chord forces due to dead load those be gained from Tables 5 and 6 are $3 \%$ and $5 \%$ of the respective yield force. These percentages become high in the full scale composite joists, which indicate the importance of accounting for the dead load.top chord and bottom chord forces are tabulated in Tables 5 and 6 respectively.

\subsection{Calculated Moment Capacity}

Predicted moment capacities are computed using the flexural models developed by Azmi $(1972)^{\mathbf{3}}$. The strength of under-connected joists is derived from the internal resisting couples formed by $\boldsymbol{C}_{\boldsymbol{c}}$ and by $\boldsymbol{N}_{\boldsymbol{c}}$ separated from tension force $\boldsymbol{T}_{\boldsymbol{c}}$ a distance $\boldsymbol{e}$ and $\boldsymbol{e}^{\prime}$ respectively. For the overconnected joists, chord forces $\boldsymbol{N}_{\boldsymbol{c}}$ and $\boldsymbol{T}_{\boldsymbol{c}}$ separated from the slab compression resultant $\boldsymbol{C}_{\boldsymbol{c}}$ by lever arms $\boldsymbol{e}$ and $\boldsymbol{e}_{\boldsymbol{t}}$, provide the internal moment. Resultant chord forces $\boldsymbol{N}_{\boldsymbol{c}}$ and $\boldsymbol{T}_{\boldsymbol{c}}$, are assumed to act at the centroid of the chord crosssectional area and they do not depend on the degree to which the chord is stressed, as should be the case when the member is not fully developed. Consequently the distance between the chord forces, $\boldsymbol{e}^{\prime}$, does not change for a given joist, a simplification in the models. The Whitney equivalent stress block, of height $\boldsymbol{a}=\boldsymbol{C}_{\boldsymbol{c}} / \mathbf{0 . 8 5} \boldsymbol{f}_{\boldsymbol{c}}^{\prime}$ $\boldsymbol{b}$, is assumed for distribution of concrete stresses. In this study, $\left(f_{c}^{\prime}=27\right.$ and $26.5 \mathrm{MPa}$ for $\mathrm{NWC}$ and LWC respectively) in addition the effective slab width (b) was taken $400 \mathrm{~mm}$. The resultant compressive force in the concrete act at a distance $\boldsymbol{a} / 2$ measured from the face of the slab. Therefore, the lever arm between the concrete compressive force and the bottom chord force is computed as:

$$
e=d_{\text {joist }}+t_{s}-y_{b c}-a / 2 \quad \ldots \ldots 4
$$

And the separation between the concrete compressive force and the top chord centroid is:

$$
e_{t}=y_{t c}+t_{s}-a / 2 \quad \ldots . .5
$$

The models assume that the depth of concrete compressive block does not exceed the height of concrete over the deck ribs when oriented perpendicular to the joist. Table 7 gives the geometric properties of each cross-section. Three moment equations can be written for the underconnected cases, Fig. 6-a, and three for overconnected cases Fig.6-b. For a typical underconnected joist, these equations are:

$$
\begin{gathered}
M_{c}=C_{c} . e+N_{c} . e^{\prime} \\
M_{c}=C_{c} . e_{t}+T_{c} . e^{\prime} \ldots .66 \\
M_{c}=T_{c} e-N_{c} . e_{\mathrm{t}} \ldots . .7
\end{gathered}
$$

For the over-connected joists and If the moments are taken about the bottom chord, the top chord and the resultant slab force, respectively.

$$
\begin{array}{ll}
M_{c}=C_{c} \cdot e-N_{c} \cdot e & \ldots .9 \\
M_{c}=C_{c} e_{t}+T_{c} \cdot e & \ldots .10 \\
M_{c}=T_{c} e+N_{c} \cdot e_{\mathrm{t}} & \ldots . .11
\end{array}
$$

These are the corresponding equations used to describe the internal moment resistance. Note that 


\section{NJES Vol.21 No.3, 2018}

equations containing the top chord force are the same except for the sign of this force. Also, identical equations result when moments are summed about the top chord. Combining the equations that include the top chord force, the equations reduce to:

$$
\begin{array}{ll}
M_{c}=C_{c} \cdot e \mp N_{c} \cdot e^{\prime} & \ldots .12 \\
M_{c}=C_{c} e_{t}+T_{c} \cdot e^{\prime} & \ldots .113 \\
M_{c}=T_{c} e \mp N_{c} \cdot e_{\mathrm{t}} & \ldots .14
\end{array}
$$

The application of these equations is limited to Cases 1 through 5, and it is assumed that the concrete crushing strength exceeds the shear connection strength, the resultant slab force can be replaced by the shear connection force $\left(\boldsymbol{C}_{\boldsymbol{c}}\right.$ can be replaced by $\sum \boldsymbol{Q}_{c}$ ), so that:

$$
\begin{aligned}
& M_{c}=\sum Q_{c} . e \mp N_{c} . e \quad \ldots . .15 \\
& M_{c}=\sum Q_{c} \cdot e_{t}+T_{c} \cdot e^{\prime} \ldots .16 \\
& M_{c}=T_{c} . e \mp N_{c} . e_{\mathrm{t}} \quad \ldots . .17
\end{aligned}
$$

Predicated dead load moments at mid-span are calculated using the formula:

$$
M_{d c}=w_{d c} L / 8 \quad \ldots . .18
$$

where $\boldsymbol{w}_{d c}$ is the uniformly distributed dead load of the system which in this study equal to $3.7 \mathrm{kN}$ for joists of NWC slab and $3.4 \mathrm{kN}$ for joist of LWC slab. Dead loads are the non-composite joist load ; ( concrete of slab, steel deck, spreader and joist self-weight).The calculated moment resistance is the difference between the total load moment and the dead load moment. Calculated moments are summarized in Table 8 .

$$
M_{a c}=M_{c}-M_{d c}
$$

\subsection{Calculated Joist Load}

Predicted Joist load is the final variable to be found in the initial sequence of calculations. The Joist load is back calculated from the calculated mid-span moment assuming seven point loads equally spaced along the joist as shown in Fig.7. Summing moments about mid-span:

$$
M_{c}+F(L / 6+2 L / 6+3 L / 6)-R(L / 2)=0
$$

Where $\boldsymbol{L}$ is the joist span and $\boldsymbol{F}$ is the seventh point loads which will produce the calculated total

\section{Hadeed et al., pp.356-367}

moment, $\boldsymbol{M}_{c}$ is found in the previous section. This can be rewritten as

$$
\begin{aligned}
& M_{c}+F(L / 6+2 L / 6+3 L / 6)-3.5 \\
& M_{c}-0.75 F L=0
\end{aligned}
$$

from which $\boldsymbol{F}=\boldsymbol{M}_{c} / \mathbf{0 . 7 5} \boldsymbol{L}$. The predicted joist load $\boldsymbol{P}_{\boldsymbol{c}}=\mathbf{7} \boldsymbol{F}(\boldsymbol{k N}) . \boldsymbol{M}_{\boldsymbol{c}}$ includes both the dead load moment and the applied load moment; thus, the $\boldsymbol{P}_{\boldsymbol{c}}$ is the total joist load. The calculated joist dead load is computed in $\mathrm{kN}$ by multiplying the uniformly distributed dead load by the theoretical joist span

$$
P_{d c}=w_{d c} \cdot L
$$

The applied load is the difference between the total load and the dead load.

$$
P_{a c}=P_{c}-P_{d c}
$$

Calculated joist loads are given in Table 9 .

The calculated dead weight is used in place of a measured dead weight. The experimental dead load $\left(\boldsymbol{P}_{d e}\right)$ is shown in a single column with the calculated dead load in Table 9.The applied load, that load which is introduced after the section is considered composite, is from ram load. The ram load is distributed through spreader beams and then the ram load was considered subjected to seven joint points as shown in Fig.8. The models assume that two of the three forces will reach their capacity under applied load ( $\boldsymbol{C}$ and $\boldsymbol{N}$ for Case 1; $C$ and $T$ for Cases 2,3,4; $N$ and $T$ for Case 5 ).

Experimental and calculated member loads are compared at the applied load stage in the final column of Table 9.Test with ratio less than unity carried less than calculated. Joists that have lower load values, will be linked to the low of the web inclination as for joist 4 , light weight slab as joist 6 and to the long headed shear connectors as for joist 7 due to the subjection to the excess moments at the heads of the studs, these are shown in Table 9.

$$
P_{e}=P_{d e}+P_{a e}
$$

Table 5: Calculated and experimental top chord forces

\begin{tabular}{|c|c|c|l|c|l|l|l|}
\hline Joists & $\begin{array}{c}N_{y} \\
(k N)\end{array}$ & $\begin{array}{c}N_{d c} \\
(k N) \\
E q .\end{array}$ & $\begin{array}{l}N_{a c} \\
(k N) \\
E q .2\end{array}$ & $\begin{array}{c}N_{c} \\
(k N) \\
\text { Azmi model }\end{array}$ & $\begin{array}{l}N_{d e} \\
(k N) \\
E q .1\end{array}$ & $\begin{array}{l}N_{a e}(k N) \\
\text { Table } 2\end{array}$ & $\begin{array}{l}N_{e}(k N) \\
E q .23\end{array}$ \\
\hline CSJ-1 & 133.5 & 6.0 & -120.4 & -114.4 & 6.0 & -55.74 & -49.74 \\
\hline CSJ-2 & 133.5 & 6.0 & -120.4 & -114.4 & 6.0 & -28.14 & -22.14 \\
\hline CSJ-3 & 133.5 & 6.0 & 29.62 & 35.62 & 6.0 & -39.93 & -33.25 \\
\hline CSJ-4 & 133.5 & 6.0 & -120.4 & -114.4 & 6.0 & -29.70 & -23.70 \\
\hline CSJ-5 & 133.5 & 6.0 & -120.4 & -114.4 & 6.0 & -46.10 & -40.10 \\
\hline CSJ-6 & 133.5 & 5.6 & -85.0 & -79.4 & 5.6 & -18.87 & -13.27 \\
\hline CSJ-7 & 133.5 & 6.0 & -139.5 & -133.5 & 6.0 & -19.33 & -13.33 \\
\hline
\end{tabular}

Negative values are tension 
Table 6: Calculated and experimental bottom chord forces

\begin{tabular}{|l|c|c|c|c|c|c|c|}
\hline Joists & $\boldsymbol{T}_{\boldsymbol{y}}(\boldsymbol{k N})$ & $\boldsymbol{T}_{\boldsymbol{d c}}(\boldsymbol{k N})$ & $\begin{array}{c}\boldsymbol{T}_{\boldsymbol{a c}}(\boldsymbol{k N}) \\
\boldsymbol{E q . 2}\end{array}$ & $\begin{array}{c}\boldsymbol{T}_{\boldsymbol{c}}(\boldsymbol{k N}) \\
=\boldsymbol{T}_{\boldsymbol{y}}\end{array}$ & $\boldsymbol{T}_{\boldsymbol{d e}}(\boldsymbol{k N})$ & $\begin{array}{c}\boldsymbol{T}_{a e}(\boldsymbol{k N}) \\
\text { Table } 2\end{array}$ & $\begin{array}{c}\boldsymbol{T}_{\boldsymbol{e}}(\boldsymbol{k N}) \\
\boldsymbol{E q . 2 4}\end{array}$ \\
\hline CSJ-1 & 185.62 & 6 & 179.62 & 185.62 & 6 & 185.62 & 191.62 ,yield \\
\hline CSJ-2 & 185.62 & 6 & 179.62 & 185.62 & 6 & 185.64 & 191.64 ,yield \\
\hline CSJ-3 & 185.62 & 6 & 179.62 & 185.62 & 6 & 185.63 & 191.63 ,yield \\
\hline CSJ-4 & 185.62 & 6 & 179.62 & 185.62 & 6 & 185.62 & 191.62 ,yield \\
\hline CSJ-5 & 185.62 & 6 & 179.62 & 185.62 & 6 & 185.63 & 191.63 ,yield \\
\hline CSJ-6 & 185.62 & 5.6 & 180.02 & 185.62 & 5.6 & 185.62 & 191.62 ,yield \\
\hline CSJ-7 & 185.62 & 6 & 179.62 & 185.62 & 6 & 185.62 & 191.62 ,yield \\
\hline
\end{tabular}

All values are tension

Table 7: Parameters for calculated moment capacity

\begin{tabular}{|l|c|c|c|c|c|c|c|c|}
\hline Joists & $\begin{array}{c}\boldsymbol{d}_{\text {joist }} \\
(\mathbf{m m})\end{array}$ & $\begin{array}{c}\boldsymbol{t}_{\boldsymbol{s}} \\
(\mathbf{m m})\end{array}$ & $\begin{array}{c}\boldsymbol{y}_{\boldsymbol{t c}} \\
(\mathbf{m m})\end{array}$ & $\begin{array}{c}\boldsymbol{y}_{\boldsymbol{b c}} \\
(\mathbf{m m})\end{array}$ & $\begin{array}{c}\boldsymbol{e}^{\prime} \\
(\mathbf{m m})\end{array}$ & $\begin{array}{c}\boldsymbol{a}= \\
\boldsymbol{C}_{\boldsymbol{c}}{ }^{*} / \mathbf{O . 8 5}^{\prime}{ }_{\boldsymbol{c}} \boldsymbol{b} \\
(\mathbf{m m})\end{array}$ & $\begin{array}{c}\boldsymbol{e} \\
(\mathbf{m m})\end{array}$ & $\begin{array}{c}\boldsymbol{e}_{\boldsymbol{t}} \\
(\mathbf{m m})\end{array}$ \\
\hline CSJ-1 & 235 & 60 & 9.12 & 10.922 & 214.96 & 32.7 & 267.73 & 52.77 \\
\hline CSJ-2 & 235 & 60 & 9.12 & 10.922 & 214.96 & 32.7 & 267.73 & 52.77 \\
\hline CSJ-3 & 235 & 60 & 9.12 & 10.922 & 214.96 & 16.34 & 275.91 & 60.95 \\
\hline CSJ-4 & 235 & 60 & 9.12 & 10.922 & 214.96 & 32.7 & 267.73 & 52.77 \\
\hline CSJ-5 & 235 & 60 & 9.12 & 10.922 & 214.96 & 32.7 & 267.73 & 52.77 \\
\hline CSJ-6 & 235 & 60 & 9.12 & 10.922 & 214.96 & 29.4 & 269.4 & 54.42 \\
\hline CSJ-7 & 235 & 60 & 9.12 & 10.922 & 214.96 & 38.13 & 265.00 & 50.1 \\
\hline
\end{tabular}

$* \mathbf{C}_{\mathbf{c}}=\sum \mathbf{Q}_{\mathrm{c}}$

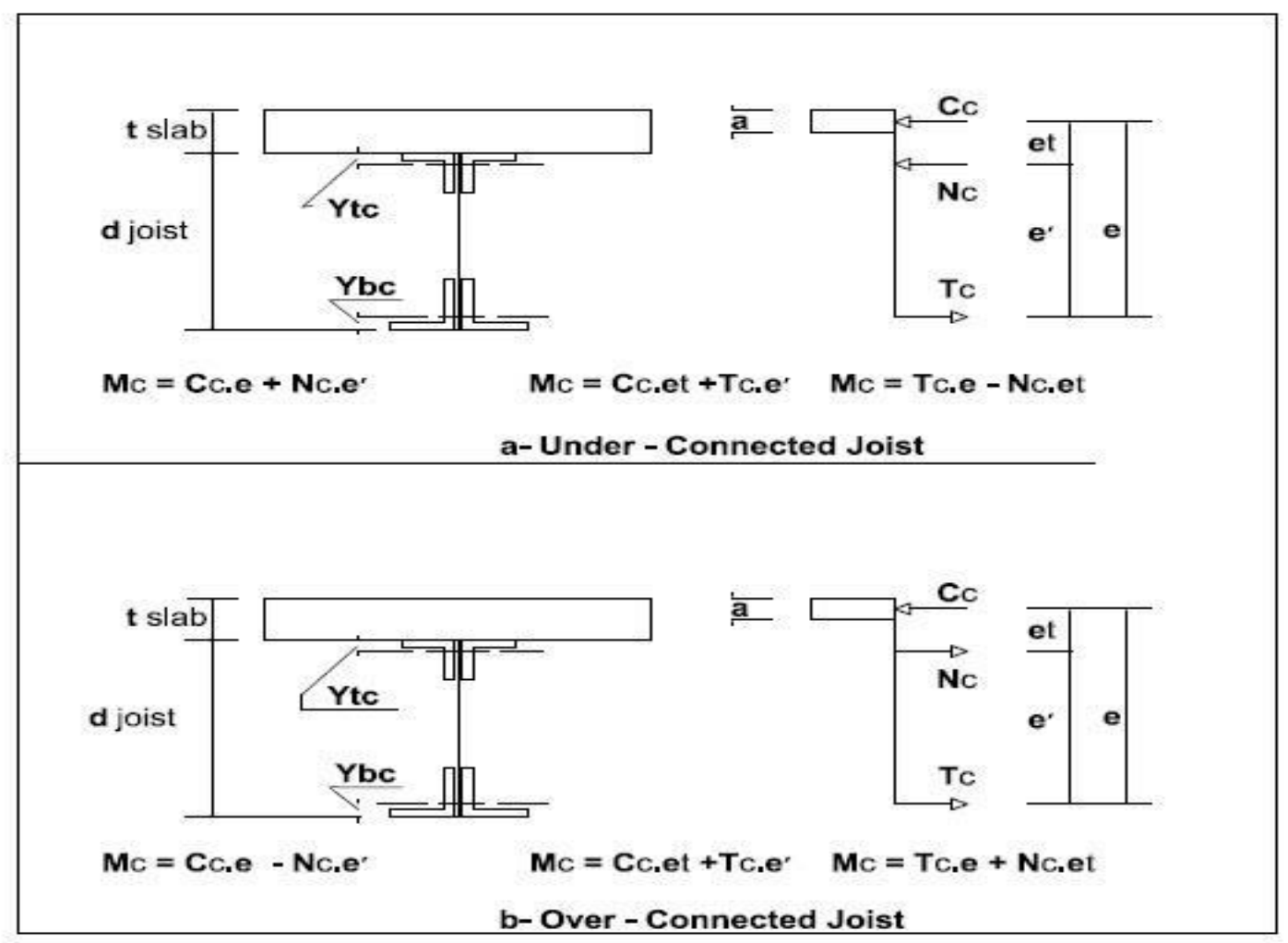

Figure 6: Calculated moment capacity of composite joist 

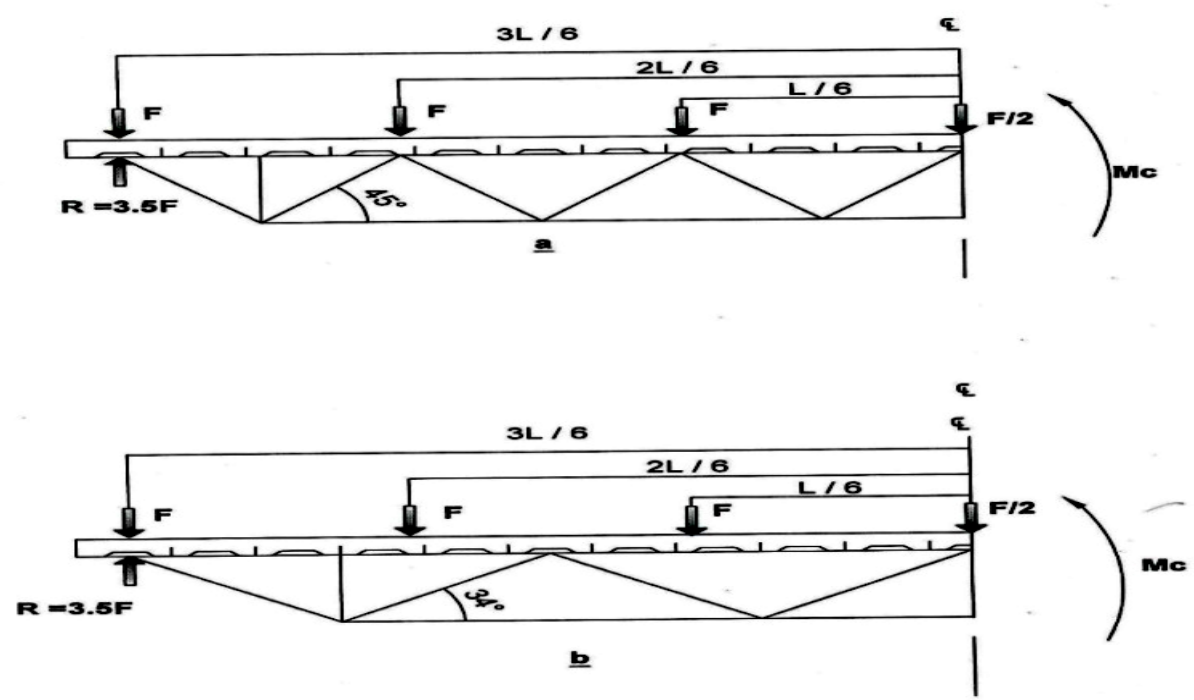

Figure 7: Calculated load and mid-span moment a- joist (1, 2, 3, 5, 6, 7), b- joist 4

Table 8: Calculated and experimental mid-span moments

\begin{tabular}{|c|c|c|c|c|c|c|}
\hline Joists & $\begin{array}{c}M_{d c}, M_{d e} \\
(k N . m) \\
E q .18\end{array}$ & $\begin{array}{c}M_{a c}(k N . m) \\
E q .19\end{array}$ & $\begin{array}{c}M_{c}(k N . m) \\
E q .15\end{array}$ & $\begin{array}{c}M_{a e} \\
(k N . m) \\
E q .23\end{array}$ & $\begin{array}{c}M_{e} \\
(k N . m) \\
E q .24\end{array}$ & $M_{a e} / M_{a c}$ \\
\hline CSJ-1 & 1.3 & 54.43 & 55.73 & 45.73 & 47.03 & 0.84 \\
\hline CSJ-2 & 1.3 & 54.43 & 55.73 & 41.61 & 42.91 & 0.77 \\
\hline CSJ-3 & 1.3 & 47.743 & 49.043 & 40.7 & 42 & 0.85 \\
\hline CSJ-4 & 1.3 & 54.43 & 55.73 & 36.63 & 37.93 & 0.67 \\
\hline CSJ-5 & 1.3 & 54.43 & 55.73 & 44.6 & 45.9 & 0.82 \\
\hline CSJ-6 & 1.2 & 53.12 & 54.32 & 39.3 & 40.5 & 0.74 \\
\hline CSJ-7 & 1.3 & 54.57 & 55.87 & 40.34 & 41.64 & 0.74 \\
\hline
\end{tabular}

Table 9: Calculated and experimental member load

\begin{tabular}{|c|c|c|c|c|c|c|}
\hline \multirow{2}{*}{ Joists } & $\begin{array}{c}\boldsymbol{P}_{d c}, \boldsymbol{p}_{d e} \\
\boldsymbol{k} \boldsymbol{N}\end{array}$ & $\begin{array}{c}\boldsymbol{P}_{\boldsymbol{a c}} \\
\boldsymbol{k} \boldsymbol{N} \\
\boldsymbol{E q . 2 1}\end{array}$ & $\begin{array}{c}\boldsymbol{P}_{\boldsymbol{c}} \\
\boldsymbol{k} \boldsymbol{E q . 2 0}\end{array}$ & $\begin{array}{c}\boldsymbol{P}_{a e} \\
\boldsymbol{k N} \\
\text { laboratory } \\
\text { test }\end{array}$ & $\begin{array}{c}\boldsymbol{P}_{\boldsymbol{e}} \\
\boldsymbol{k} \boldsymbol{E} \\
\boldsymbol{E q . 2 2}\end{array}$ & $\begin{array}{c}\boldsymbol{P}_{a e} / \boldsymbol{P}_{\boldsymbol{a c}} \\
\boldsymbol{k} \boldsymbol{N}\end{array}$ \\
\hline CSJ-1 & 3.7 & 180.77 & 184.47 & 151.35 & 155.1 & 0.84 \\
\hline CSJ-2 & 3.7 & 180.77 & 184.47 & 137.7 & 141.4 & 0.77 \\
\hline CSJ-3 & 3.7 & 158.63 & 162.33 & 134.6 & 138.3 & 0.85 \\
\hline CSJ-4 & 3.7 & 180.77 & 184.4 & 121.22 & 124.92 & 0.67 \\
\hline CSJ-5 & 3.7 & 180.77 & 184.47 & 147.5 & 151.2 & 0.82 \\
\hline CSJ-6 & 3.4 & 176.4 & 179.8 & 130.03 & 133.43 & 0.74 \\
\hline CSJ-7 & 3.7 & 208.3 & 184.93 & 133.5 & 137.2 & 0.74 \\
\hline
\end{tabular}

\section{Experimental Value}

\subsection{Experimental Moment Capacity}

The experimental moments are found at the dead load stages, applied load stages, and then combined to obtain the total experimental moment as in table 8 . In this study the measured chord forces at dead load stage were not sensed (as they are very small). Hence the experimental dead load moment values are listed in the same column of the calculated dead load moment values in Table 8. The experimental applied moment is computed using statics and the maximum applied load $\boldsymbol{P}_{\boldsymbol{a}}$ measured during testing depending on Fig. 8.The experimental applied load is distributed through the spreader beams through the seven joint points with $\boldsymbol{A}=\boldsymbol{P}_{\boldsymbol{a} e}$ / 7. Referring to Eq. (20), the resulting mid-span moment can be written

$$
M_{a e}=0.75 \mathrm{~A} . L
$$

Where, $\boldsymbol{L}$ is the joist span. The experimental applied load moment at mid-span, $\boldsymbol{M}_{\boldsymbol{a}}$ is to be compared to the calculated applied load moment, Mac which is shown in the final column of Table 


\section{NJES Vol.21 No.3, 2018}

8. Ratios of experimental to calculated applied moments are identical to the applied member load ratios. The total experimental moment is again the sum of the experimental moments due to dead and applied loads.

$$
M_{e}=M_{d e}+M_{a e}
$$

The total moments determined in this way are given in Table 8, for comparison to the calculated moments. The percentage of calculated total moment is not given, but the applied moment ratios would be similar to those at the applied load stage.

\subsection{Experimental Chord Forces}

In general as with experimental total applied load and the resulting mid-span moment, experimental chord forces are measured at the dead load stage and at the applied load stage when the mid span bottom chord (BC3) is yielded, then they are superimposed to obtain the total chord force at failure. In this research, values of the measured or experimental chord forces due to dead load are considered the same as those of the corresponding calculated ones, whereas the experimental top and bottom applied chord forces were taken from the strain measurements. These values are listed as $\boldsymbol{T}_{a e}$ in Table 2 and 5, also as $N_{a e}$ in Table 2 and 6 . Under applied loading, the top chord forces may be tensile or compressive while the bottom chord is always tensile. The total experimental chord force is the sum of the dead load force and the applied load force,

$$
\begin{array}{cc}
N_{e}=N_{d e} \mp N_{a e} & \ldots .25 \\
T_{e}=T_{d e}+T_{a e} & \ldots .26
\end{array}
$$

Because the applied forces $\boldsymbol{N}_{a e}$ and $\boldsymbol{T}_{\boldsymbol{a} e}$ represent the values at failure, $T_{e}$, and $N_{e}$ are the total chord forces at failure. These values arelisted in Tables 5 and 6 , respectively. Joists 1, 2, 4, 5, 6 and 7 behaved as over connected joists as expected, according to case 4 of the flexural model adapted by Azmi (1972) ${ }^{3}$. Bottom chords suffered from tensile yielding while the top chords did not reach their critical tensile limits, they were close to that expected based on the

\section{Hadeed et al., pp.356-367}

ultimate strength models. However joist 3 that was essentially designed as under connected joist, Case 2, had its top chord undergoing tension action, so the joist behaved in an over connection manner of the lower limit condition case 4, it may be due to the contribution of the metal deck which was efficiently welded to the top chord causing increase of the horizontal shear resistance thus keeping the neutral axis within the compression zone.

\subsection{Experimental Shear Connection}

The experimental shear connection force (i.e., shear connection force being supplied under test load) is back calculated based on the measured moment and the assumed flexural model. The equations representing in the flexural model that include the shear connection force are given previously as:

$$
\begin{aligned}
& M_{c}=\sum Q_{c} . e \mp N_{c} . e^{\prime} \quad \ldots . .15 \\
& M_{c}=\sum Q_{c} \cdot e_{t}+T_{c} \cdot e^{\prime} \quad \ldots .16
\end{aligned}
$$

Either of these equations can be used to back calculate the shear connection. Because the experimental shear connection is to be found at the applied load stage, applied load variables are substituted for the total load variables, and these equations become

$$
\begin{aligned}
& \sum Q_{a e} \cdot e \mp N_{a} \cdot e^{\prime}=M_{a e} \quad \ldots .27 \\
& \sum Q_{a e} \cdot e_{t}+T_{a} \cdot e^{\prime}=M_{a e}
\end{aligned}
$$

The shear connection force is the less sensitive to changes in the assumed force when using Eq. (27) because the moment arms are more nearly equal. However, this equation can be difficult to apply to joists that are near the balanced condition ${ }^{4}$. Previous researches (Cran 19716, Gibbing et al. $1991^{7}$ ) have neglected any contribution of the top chord when predicting the composite joist moment capacity. Although theoretically either of the above equations could be used for back calculation, equation (27) was chosen for the test joists in this series. The ratio $\sum \boldsymbol{Q}_{a \boldsymbol{e}} / \sum \boldsymbol{Q}_{a c}$ is a measure of how the provided shear connection force compares to that previously predicted as shown in table 10 . 

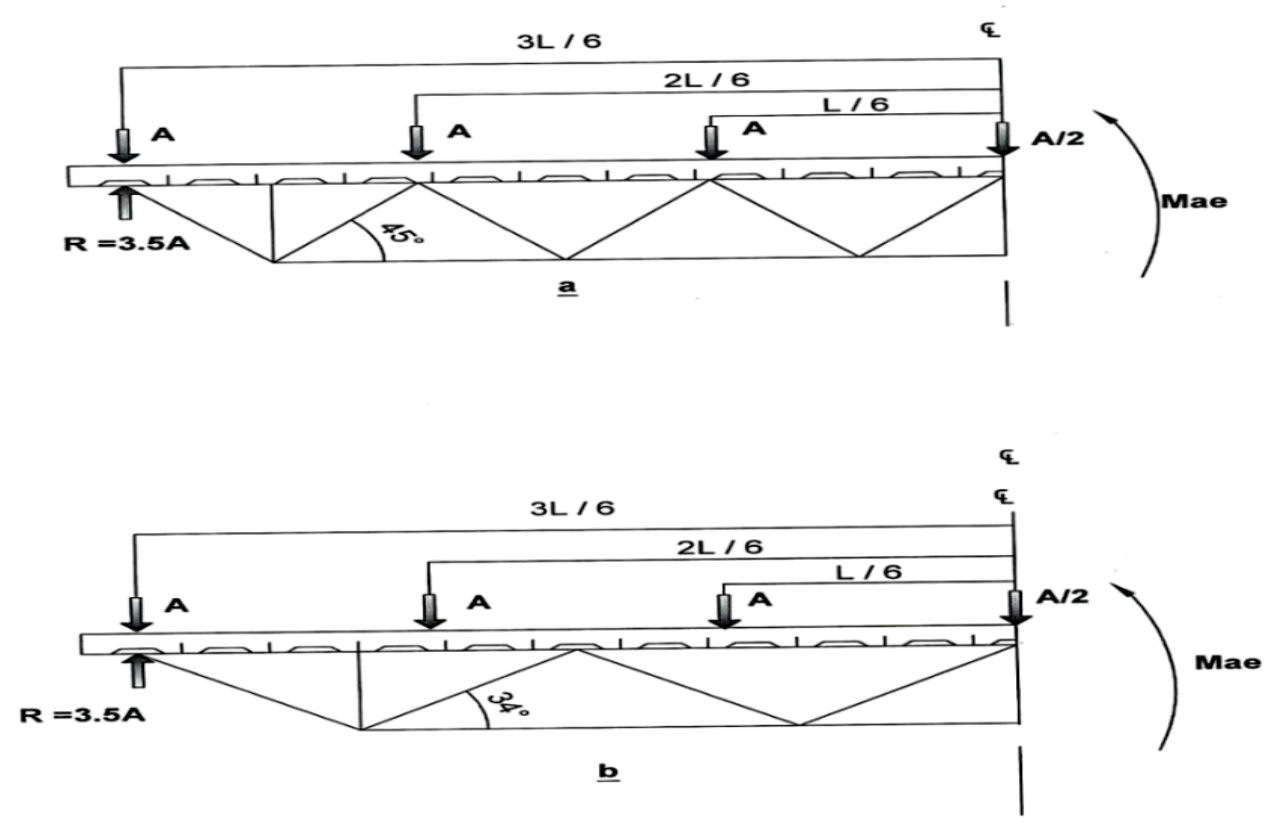

Figure 8: Member load and experimental mid-span bending moment a- joists $(1,2,3,5,6,7)$, b- joist 4 .

Table 10: Experimental shear connection

\begin{tabular}{|c|c|c|c|c|c|c|c|}
\hline Joists & $\begin{array}{l}N a \\
(k N)\end{array}$ & $\begin{array}{c}N_{a e} \\
(k N)\end{array}$ & $\begin{array}{c}T a \\
(k N)\end{array}$ & $\begin{array}{c}\text { Tae } \\
(k N)\end{array}$ & $\begin{array}{c}\sum Q_{a c}(k N) \\
\text { From } \\
\text { push-out test }\end{array}$ & $\begin{array}{r}\sum Q_{a e} \\
(k N) \\
E q .27\end{array}$ & $\sum \boldsymbol{Q}_{a e} / \sum \boldsymbol{Q}$ \\
\hline CSJ-1 & -55.74 & -55.74 & 159.6 & 185.62 & 300 & 215.34 & 0.72 \\
\hline CSJ-2 & -28.14 & -28.14 & 149.87 & 185.64 & 300 & 178.01 & 0.60 \\
\hline CSJ-3 & -39.93 & -39.93 & 138.69 & 185.63 & 150 & 178.62 & 1.20 \\
\hline CSJ-4 & -29.70 & -29.70 & 130.96 & 185.62 & 300 & 160.66 & 0.54 \\
\hline CSJ-5 & -46.10 & -46.10 & 157.5 & 185.63 & 300 & 203.6 & 0.68 \\
\hline CSJ-6 & -18.87 & -18.87 & 142.07 & 185.62 & 265 & 160.94 & 0.61 \\
\hline CSJ-7 & -19.33 & -19.33 & 148.58 & 185.62 & 350 & 167.91 & 0.48 \\
\hline
\end{tabular}

\section{Conclusions}

1. The proposed flexural model has proved to be acceptable for analyzing the composite open web steel joists with the exception of the joist of web members inclined by an angle less than $45^{\circ}$ (joist 4) .This abnormally configured the composite open web steel exhibited $67 \%$ of the theoretically predicted load carrying-capacity and internal bending moment resistance.

2. Composite steel joist (CSJ-1), under connected joist ( CSJ-3), and rounded web joist (CSJ-5) exhibited load and moment capacity coinciding by $84 \%, 85 \%$ and $82 \%$ of analytical model values respectively, followed by $77 \%$ and $74 \%$ for the joists of variables had been ordered, a non uniform distributed studs(CSJ-2) and LWC slab (CSJ-6). Those values that discussed above considered acceptable.

According to that, the reduction factor $(\phi)$ can be taken, 0.7 for joists of low web inclination but may be taken 0.75 for the joists of non- uniform studs distribution, the joists of LWC slab and of long headed studs. Finally, the reduction factor $(\phi)$ can be taken 0.85 for the joists of $45^{\circ}$ web inclination, the joists of uniformly under connected studs and the joists of rounded webs.

3. Headed shear connectors are strong enough against the applied shear forces for the joists of over connection. The joist of under shear connection suffered from large applied horizontal shear force ( $120 \%$ of the calculated). The concrete crushing around the studs caused up lift failure before the shearing of the studs. That was due to the weakness of concrete bearing at the profile of the studs.

4. Classification of the composite open web steel joists (COWSJs) depends on the provided shear connectors, which should be quantitatively proportioned carefully to give accurate top chord strength prediction so it has been useful to further 


\section{NJES Vol.21 No.3, 2018}

classify the joist into five cases of the adopted analytic flexural model.

\section{References:}

1. Supplement No 1," Standard specifications for Composite steel Joists and code of standard practice", Steel Joist institute (SJI), Vol. 32 ,December, 2010.

2. David Samuelson,"Composite Steel Joists", "Engineering Journal / Third Quarter, 2002, $111 \mathrm{p}$.

3. Azmi, M. H., "Composite Open-Web Trusses with Metal Cellular Floor", M.Sc. Thesis, McMaster University, Hamilton, Ontario, Canada, April , 1972.

4. Douglas F. Lauer," Ultimate strength analysis of composite and fully composite open - web steel joists", M.Sc. Thesis,

\section{Hadeed et al., pp.356-367}

Virginia Polytechnic Institute and state University, October , 1994.

5. BS 5950: Part 3: section 3.1 "Code of Practice for Design of Simple and Continuous Composite Beams". British Standards Institution, London, 1990.

6. Cran, J. A. "Design and Testing Composite Open Web Steel Joists", Proc. First Specialized Conference on Cold Formed Steel Structures, University of Missouri, MO., 1971, pp.186-197.

7. Gibbings, D. R. and Easterling, W. S., "Strength of Composite Long Span Joists", Report CE/VPI-ST91/02, Department of Civil and Environmental Engineering, Virginia Polytechnic Institute and State University, Blacksburg, VA, 1991

\section{الموديل التحليلي وتقييم النتائج لتصرف العتبات الفولاذية المركبة المفتوحة الوترات

$$
\text { قلسم الهندسة المعمارية }
$$$$
\text { كلية الاسر اء الجامعة المعارية }
$$

$$
\text { قليث خالد الحديثي }
$$

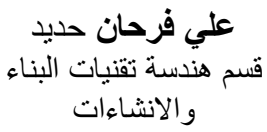

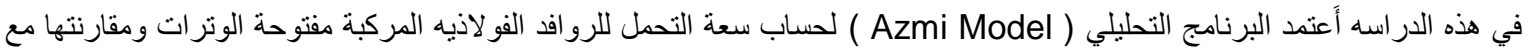

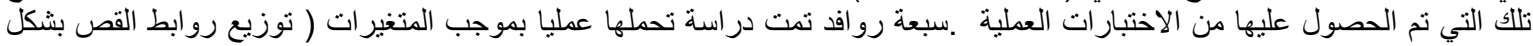

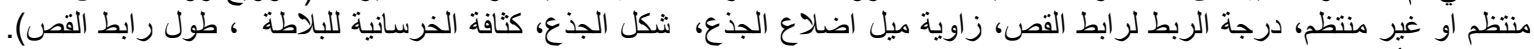

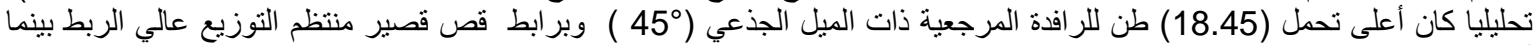
أقل تحمل هو للر افدة ذات الميل الجذعي (45.

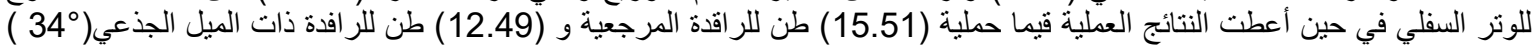
وذات رابط قص قصير منتظم التوزيع عالي الربط .تراوحت سعة التحمل العملية للروافد من ( 67\% - 85\% من من النتائج النظرية

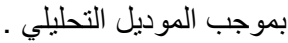

